\title{
«Mámoa 87 de Serra Faladora»: un túmulo megalítico del Norte de Galicia
}

\author{
R. Fábregas Valcarce * \\ J. SUAREZ OTERO **
}

Abstract.-Mámoa 87th of Serra Faladora: A megalithic mound from the extreme North of Galicia (NW. Spain).

The outstanding work of survey and digging accomplished by the late F. Maciñeira in the first decades of the present century was unfortunately not continued until recent years, when new excavations with a modern methodology, together with a reappraisal of the materials recovered by Maciñeira are throwing new light to the characteristics of the megalithic burial in the far North of Galicia. In this paper we are dealing with the analysis of the artefacts found in the mound 87th of Serra Faladora, which in spite of its ruinous condition at the time of Macineira's discovery might be possibly classified under the label of passage grave, though with some remarkable features like the extreme eccentricity of the chamber and the presence of a pit dug into the bedrock under the mound and filled with stones and earth with traces of fire (fig. 2A). The material items found in the disturbed chamber are very much in agreement with the typical set of Galician megalithic grave goods: ground stone axes, flint blades and pottery with simple forms and no decoration (figs. 3-6). However, the mound 87 th detaches itself from the local pattern because of

* Departamento de Historia 1; Facultade de Xeografía e Historia; 15703-Santiago de Compostela.

** Pexigo de Abaixo, 31; 15703-Santiago de Compostela 
the number and variety of goods which is larger than usual. At the same time, other features, like the absence of arrowheads, are in full agreement with the pattern in the northern area of Galicia. In all, the mound 87th seems to reflect, with some local traits, the spread of more elaborate forms of megalithic burial in vast areas of the Northwest of the Iberian penisula around the middle of the $3^{\text {rd }}$ millenium b.C.

\section{INTRODUCCIÓN}

La figura de Federico Maciñeira (1870-1943) constituye un caso muy particular, enmarcado dentro de los albores de la arqueología gallega, a la cual hizo contribuciones de notable altura en su momento. Su actividad se ciñó casi exclusivamente a los límites de la septentrional comarca ortegalesa en la que residia, llevando a cabo una labor de catalogación y estudio de sus restos prehistóricos que, por desgracia, no ha sido superada todavía. A pesar de las lógicas limitaciones metodológicas y de su voluntario confinamiento a la categoría de erudito local, las publicaciones de Maciñeira ${ }^{1}$ todavía sorprenden por la precisión de sus descripciones, aspecto en el que contrastan favorablemente con la obra de contemporáneos suyos bastante más conocidos. Poco después de la muerte del autor, vio la luz una monografía ${ }^{2}$ dedicada en buena parte al estudio de las manifestaciones arqueológicas ubicadas en la Serra Faladora, cordal montañoso que se extiende desde As Pontes hasta Estaca de Bares y en el que las exploraciones de Maciñeira permitieron la detección de 87 túmulos, varios de los cuales fueron excavados por él mismo y descritos en el libro mencionado. Los artefactos recuperados en el curso de esas exploraciones fueron donados a la Universidad de Santiago, conservándose la mayor parte de ellos entre las colecciones del Departamento de Historia 1. Desgraciadamente, muchos de estos materiales permanecieron olvidados hasta fechas recientes en que piezas como el campanifor-

1 Entre los trabajos de mayor fuste de este autor, cabe mencionar; Notable grupo de circulos líticos y túmulos dolménicos de la cuenca superior del Eume, Arquivos do Seminario de Estudos Galegos, 2, 1929, págs. 197-230; El vaso campaniforme y condiciones de sus intactos yacimientos tumulares en la estación de Puentes, del cabo Ortegal, Atlantis, 16, 1941, págs. 356-369; Túmulos prehistóricos. Inventario descriptivo de los 286 túmulos prehistóricos hasta ahora descubiertos en la avanzada comarca del cabo Ortegal, Boletín de la Real Academia Gallega, 24, 1944-1945, págs. 15-34.

2 Macineira, F., Bares, Puerto hispánico de la primitiva navegación occidental, Santiago de Compostela 1947. 
me o los útiles de piedra pulimentada fueron revisadas y publicadas de nuevo ${ }^{3}$, mientras el conjunto de las colecciones eran objeto de una nueva catalogación ${ }^{4}$. Precisamente en el curso de esta última labor pudo localizarse buena parte de los restos cerámicos procedentes del túmulo número 87 de As Mamoelas, lo cual nos animó a abordar el análisis pormenorizado de la totalidad del ajuar recuperado asi como de las estructuras constructivas de dicho monumento.

\section{EL TÚMULO NÚMERO 87: LOCALIZACIÓN Y ESTRUCTURAS ARQUITECTÓNICAS}

Dicho monumento se asienta en el lugar de As Mamoelas, una pequeña zona aplanada sita en las últimas estribaciones de la Serra Faladora y próxima a la Villa de Bares (fig. 1); a unos $50 \mathrm{~m}$ de distancia de esa sepultura se levanta otro megalito (número 86 de la catalogación de Maciñeira). El túmulo número 87 medía $16 \mathrm{~m}$ de diámetro por $1,5 \mathrm{~m}$ de altura máxima y presentaba una forma algo ovoide, alargándose en su eje Oeste, donde por otra parte se hace más bajo. Se componía de tierra limpia, entre la que se observaban restos de combustión. En su parte central se detectó una oquedad practicada en el suelo, de unos $80 \mathrm{~cm}$ de profundidad, la cual estaba al parecer colmatada por tierra, arena y piedras con señales de fuego. Cerca de la periferia se localizó un anillo perimetral a base de piedras.

La cámara se hallaba descentrada hacia el Este (fig. 2A) y sólo conservaba tres pequeños soportes in situ (el más grande de ellos tenía $1,25 \mathrm{~m}$ de altura), fuertemente escorados hacia el interior, a pesar de haber sido calzados con pequeñas piedras. Otros tres ortostatos de mayores dimensiones estaban caídos y desplazados de su posición original, cubiertos por los escombros producidos por la violación ${ }^{5}$.

Desde luego las condiciones del yacimiento y los datos disponibles nos obligan a ser particularmente cautos a la hora de intentar reconstruir

${ }^{3}$ Fabregas Varcalce, R. y Fuente Andres, F., Aproximaciones a la cultura material del megalitismo gallego. Arqueohistórica, 2, Santiago de Compostela 1988; CRIADO BOADO, F. y Vazouez Varela, F., La cerámica campaniforme en Galicia. Cuadernos do Seminario de Sargadelos, 42, Sada 1982.

${ }^{4}$ Efectuado por uno de los autores (J.S.O) en el marco del Inventario del Patrimonio Histórico de la Universidad de Santiago de Compostela.

${ }^{5}$ MaCineIRA, Bares..., citado, págs. 119-127. 

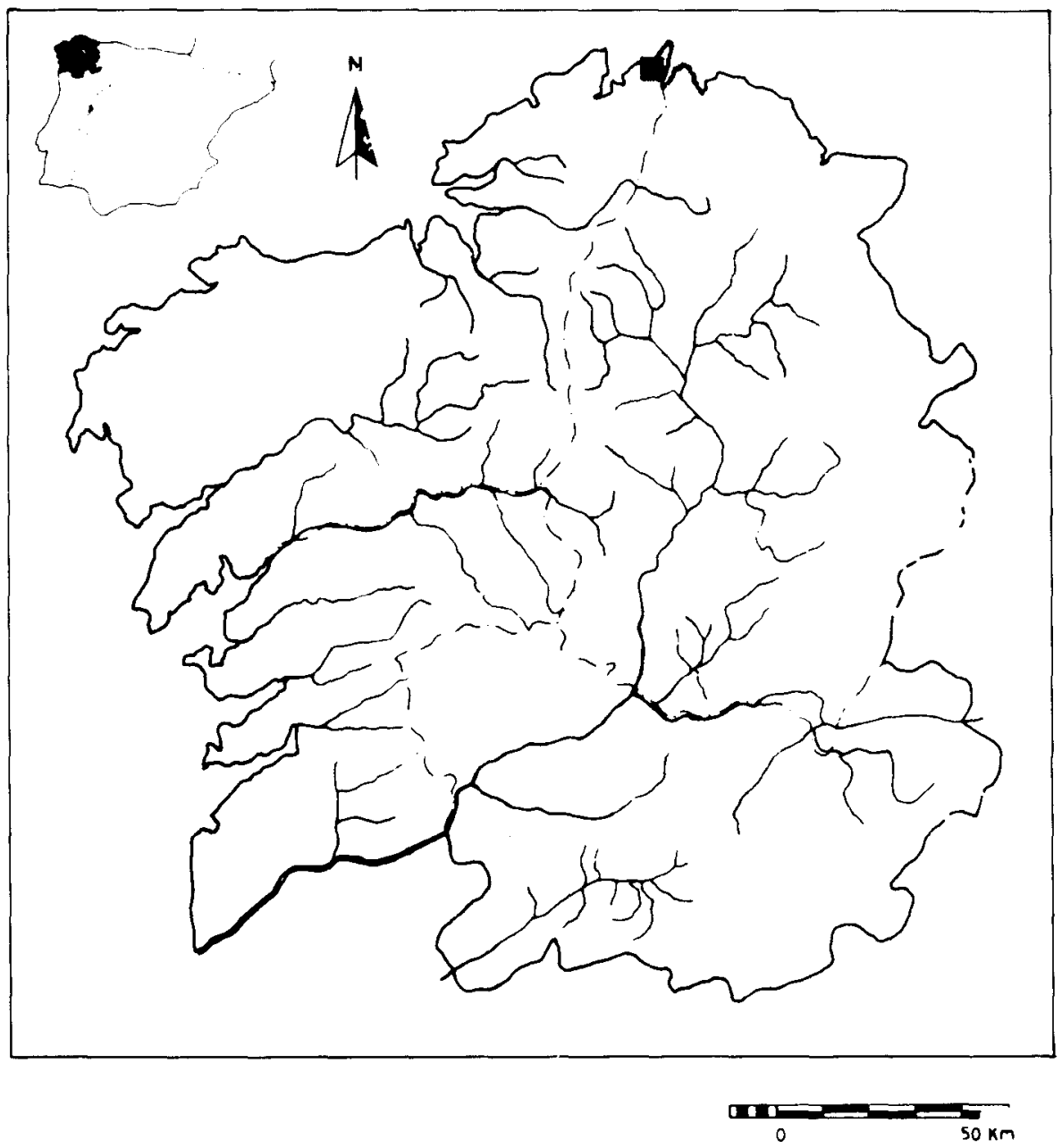

Fig. 1. Localización del túmulo 87 de Serra Faladora.

la clase de sepultura que estamos estudiando. No obstante, algunos indicios podrian permitirnos avanzar una hipótesis plausible con respecto a la estructura interna que se albergaba dentro del túmulo 87 . En primer lugar, la marcada diferencia de tamaño entre los ortostatos in situ y los desplazados parece poco coherente con una cámara poligonal simple pero en cambio sí se correspondería con lo habitual entre sepulturas de corredor. De hecho las dos losas situadas una al lado de la otra podrian haber formado parte de la entrada que se abriría hacia el NE o el SE. EI 

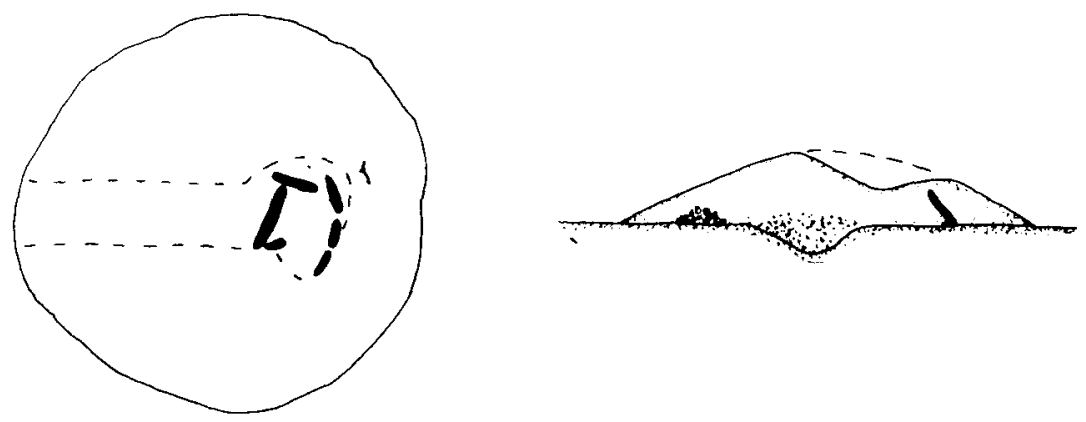

$-\mathbf{A}$

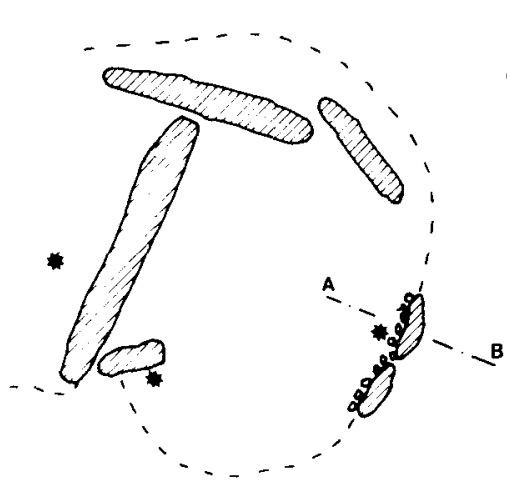

$N$
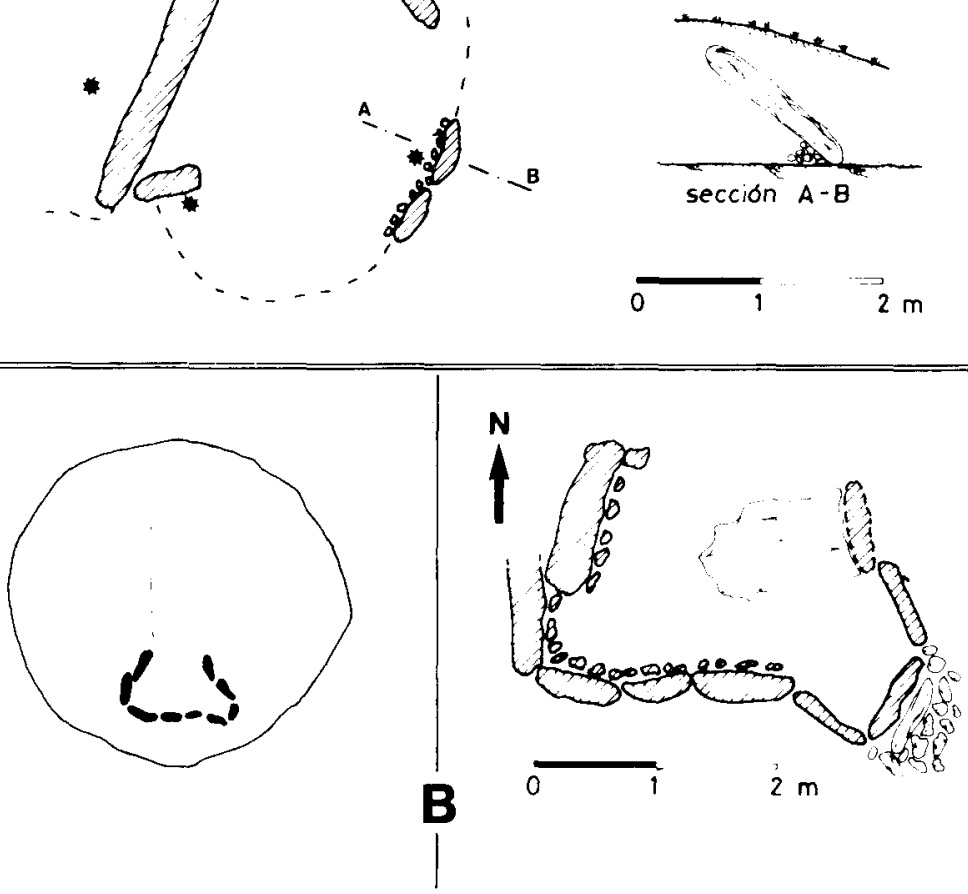

Fig. 2. Estructuras tumulares de los túmulos 87 (A) y 86 (B) de Serra Faladora, según F. Maciñeira (1947). 
túmulo vecino (número 86 ), mejor conservado en su estructura interna, podría muy bien servirnos de referencia pues se trata de una sepultura de corredor corto, en la que los ortostatos que flanquean la entrada tienen un tamaño menor que los de la cámara propiamente dicha, que además se encontraba en una posición francamente excéntrica dentro del túmulo (fig. 2B), lo cual podría estar motivado quizás por la intención de facilitar el acceso al interior del recinto sepulcral desde la periferia del monumento. Ciertamente, en el caso del túmulo número 87 , el descentramiento de la cámara, aunque evidente podría haber sido menor en el comienzo, habiendo aumentado con el transcurso del tiempo debido al desmoronamiento del túmulo hacia el Oeste, evolución que estaría indicada tanto por la menor altura que aquél presentaba en dicho sector como por el hecho de que Maciñeira refiere que el anillo lítico, el cual en principio se situaría en la periferia de la masa tumular, estaba algo metido dentro de ésta.

En resumen, creemos que a partir de la revisión de los datos proporcionados por $F$. Maciñeira, podemos defender con cierta verosimilitud que el túmulo número 87 albergaria una cámara megalítica de medianas dimensiones, provista de un corredor corto, conformando una estructura posiblemente no muy diferente de la detectada en el monumento vecino.

La fosa abierta en el terreno natural, al Oeste de la cámara, plantea una serie de cuestiones pues no constituye en modo alguno un caso único. Dentro de la misma Serra Faladora, Maciñeira refiere la aparición de estructuras semejantes en otros tres túmulos: el número 80 de Campo do Tesouro, cuya cámara había sido completamente expoliada, presentaba en lo que habria sido el suelo de ésta una excavación irregular, de perfil troncocónico, que alcanzaba los dos metros de diámetro máximo por 1,1 metros de profundidad ${ }^{6}$. También en lo que seria el suelo de la cámara del túmulo número 81 de Monte Caldeira se localizó una depresión irregular conteniendo restos de combustión ${ }^{7}$. Está, por último, el túmulo número 83 de Monte Caldeira que también poseía en el nivel inferior de la cámara una fosa irregular de perfil troncocónico, midiendo 1,3 metros de diámetro máximo por 0,75 metros de profundidad y que estaba rellena de piedras de medianas dimensiones dispuestas con cierto orden $^{8}$.

\footnotetext{
6 Macin̄eira, Bares..., citado, pág. 96.

Maciñeira, Bares..., citado, pág. 98.

Maciñeira, Bares..., citado, pág. 103
} 
En años recientes, las excavaciones efectuadas en el Noroeste han permitido el descubrimiento de estructuras excavadas en los niveles subyacentes a los túmulos, que muestran una amplia variabilidad en cuanto a características y localización. Tal vez una de las mejor documentadas es la encontrada en Santinhos 2 (Baiâo, Oporto), donde una fosa de más de $2 \mathrm{~m}$ de profundidad, conservada intacta, ocupaba el área central del monumento. En su interior, dividido por una gran laja, no se halló más que algún fragmento de molino manual y un relleno a base de capas alternantes de tierra y saproilita. Las dataciones radiocarbónicas obtenidas a partir de carbones subyacentes al monumento permiten fijar su construcción en algún momento alrededor del 3000 a.C. (fechas convencionales) ${ }^{9}$. Dentro de la misma serra da Aboboreira, la mamoa 1 de Cabritos mostraba al Este de la cámara una fosa elíptica de casi $2 \mathrm{~m}$ de largo aunque poco profunda $(25-30 \mathrm{~cm})$ cuyo interior estaba relleno de tierra y abundantes fragmentos de carbón ${ }^{10}$ que permitieron realizar una datación cuyo resultado (750 \pm 60 b.c.) ${ }^{11}$ indicaría que ésta fue abierta hacia el Bronce Final. En A Mina de Parxubeira (Mazaricos, La Coruña) se localizó una excavación de forma circular y alrededor de $0,5 \mathrm{~m}$ de diámetro en el área situada tras la cámara y en otro túmulo (número 4) de la misma necrópolis se había llevado a cabo un agujero en la roca base, situado aproximadamente en el centro del recinto megalítico ${ }^{12}$. También en el piso de la cámara de Campiños 6 (Rianxo, La Coruña) se habian hecho dos excavaciones irregulares, contiguas una a la otra, de 20 y $28 \mathrm{~cm}$ de diámetro respectivamente por $14 \mathrm{~cm}$ de profundidad máxima ${ }^{13}$.

De los ejemplos aludidos en los párrafos anteriores destaca su diversidad que, combinada en muchos casos con lo limitado de las informaciones disponibles, contribuye a mantener en la oscuridad la utilización de las estructuras excavadas en el suelo de los túmulos. No obstante, a partir de esa misma variabilidad, podemos contemplar con cierta verosimilitud el carácter plurifuncional de dichas estructuras. Cabe en primer 123.

${ }^{9}$ V. O. Jorge, Les tumulus de Châ de Santinhos, Arqueologia, 12, 1985, págs. 111 -

${ }^{10}$ V. O. Jorge, y Vilaça, R., As mámoas de Cabritos, Arqueologia, 11, 1985, pág. 56.

1 V. O. Jorge, Datas de Carbono 14 para a mámoa de Châ de Parada 4, Arqueologia, 17, 1988, pág. 124. 31 y 42.

12 Rodriguez Casal, A., La necrópolis megalitica de Parxubeira, A Coruña 1989, págs.

13 Fabregas Valcarce, r., y fuente Andres, F., Os Campiños 6. Campaña de excavación de 1984. Memoria depositada en los Servicios Técnicos de Arqueoloxia de la Xunta de Galicia, Santiago de Compostela 1989. 
lugar la posibilidad de que algunas de las excavaciones encontradas en el nivel de base de los monumentos ${ }^{14}$ se correspondiesen con actividades efectuadas con anterioridad a la erección de éste, incluso sin ninguna conexión con el mundo funerario ${ }^{15}$, o por el contrario en relación con la construcción de la sepultura que podría llevar aparejada la necesidad de ejecutar algún tipo de ritual previo que incluyese el depósito y/o cremación de ofrendas. Aquellas fosas que se localizaban en la misma cámara podrian haber jugado un papel específico en el curso de la utilización del recinto sepulcral, sin que las evidencias disponibles nos permitan ser más específicos ${ }^{16}$. En el caso de aquellos orificios de menor diámetro se podria formular como una hipótesis alternativa el que sirviesen como agujeros de poste, empleados tal vez en las tareas de construcción del monumento. Por otra parte no hay que descartar, dada la parquedad de las informaciones en algún ejemplo, la posibilidad de que dichas excavaciones en el suelo de la cámara fuesen el resultado de alguna violación particularmente contumaz.

En la fosa de Cabritos 1 tenemos un ejemplo palmario de reutilización de un túmulo megalítico dentro de una fase avanzada de la Edad del Bronce (¿incineración?), aunque el estado de remoción del túmulo y la ausencia de materiales en dicha estructura no nos permitan ir mucho más allá. Por su parte, el monumento de Châ de Santinhos 2, en el que la fosa constituye el elemento central es una buena muestra de la existencia, ya en épocas arcaicas, de una tradición tumular "paramegalítica", cuya incardinación con las arquitecturas dolménicas está todavia por establecer, aunque podriamos sugerir factores de orden funcional o cultural para explicar esa dicotomía que comienza a despuntar entre monumentos con y sin cámara ortostática.

\section{ANÁLISIS DE LOS MATERIALES}

En la publicación original, Maciñeira da a conocer con cierto detalle la localización de los objetos recuperados en el curso de su intervención

${ }^{14}$ En particular aquellas que se situaban en zonas sin señales de remoción y que no eran accesibles una vez levantado el túmulo.

${ }_{15}$ Algunos hallazgos de cerámicas $u$ otros artefactos en paleosuelos bajo los túmulos indicarian que, al menos en determinadas ocasiones, estos se alzaban sobre lugares de habitación.

${ }^{16}$ En un túmulo de Roupar (Xermade, Lugo) un pequeño agujero en el suelo, flanqueado por dos piedras asimismo de tamaño reducido parece haber servido de depósito para varios cacharros campaniformes (CRIADO, F., RAMIL, J., y VAZOUEZ, J. M., Nuevos hallazgos de campaniforme en la provincia de Lugo, Cuadernos de Estudios Gallegos, 32, 1981, pág. 455). 
arqueológica. La mayoría de las piezas aparecieron entre las tierras revueltas situadas en el área donde se habría alzado la cámara y como acertadamente señala el autor, es imposible dilucidar su ubicación primaria. Tres de los útiles pulimentados (no podemos precisar cuáles) fueron recogidos al pie de dos soportes in situ, algo también documentado en otros dos megalitos del Ortegal, lo que induce a Maciñeira a pensar que formaría parte del ritual funerario la deposición de dichos artefactos en esa particular localización. Por nuestra parte, pensamos que independientemente de que en dichas áreas periféricas del recinto sepulcral fuesen depositadas ofrendas, su exclusiva localización en esas zonas seria más bien el fruto de las sucesivas violaciones que sólo respetaron aquellas partes que por encontrarse al fondo del recinto y estar los ortostatos algo escorados hacia el interior, hacian más dificultosas las remociones.

\section{Piedra pulimentada}

N. ${ }^{\circ}$. Azuela tipo lla. Materia prima: gossan (montera de hierro). Longitud: $107 \mathrm{~mm}$. Anchura: $56 \mathrm{~mm}$. Espesor: $31 \mathrm{~mm}$. Peso: $210 \mathrm{gr}$. (fig. 3,1).

\section{LA: 1,9. A/E: 1,8. L/E: 3,4.}

Forma general: triangular. Caras: convexas. Lados: convexos. Aristas: convergentes curvas. Filo: desarrollado, tendente a semicircular. Zona activa: convexa-asimétrica. Talón (vista frontal): recto; (vista lateral): convexo. Sección transversal: elíptica. Estado de conservación: completa. Desgaste: tiene fracturas en la zona activa y en el cuepo; filo muy desgastado. Acabado: pulimento superficial.

N. ${ }^{\circ}$ 2. Hacha tipo I. Materia prima: roca serpentinica. Longitud: 93 $\mathrm{mm}$. Anchura: $41 \mathrm{~mm}$. Espesor: $36 \mathrm{~mm}$. Peso: $190 \mathrm{gr}$. (fig. 3,2).

\section{LA: 2,2. A/E: 1,1. LE: 2,5.}

Forma general: trapezoidal. Caras: convexas. Lados: rectos. Aristas: convergentes curvas. Filo: desarrollado, tendente a semicircular. Zona activa: convexo-simétrica. Talón (vista frontal): redondeado; (vista lateral): truncado. Sección transversal: cuadrangular. Estado de conservación: completa. Desgaste: tiene fracturas en la zona proximal; filo romo. Acabado: pulido integral, diferencial entre caras y lados. 

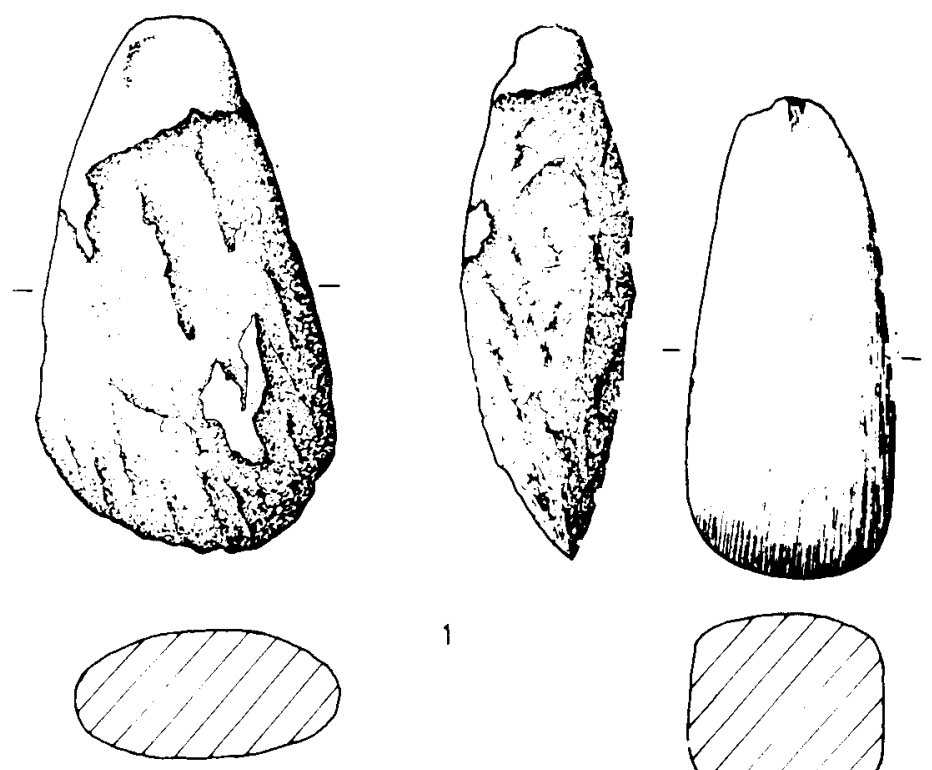

1
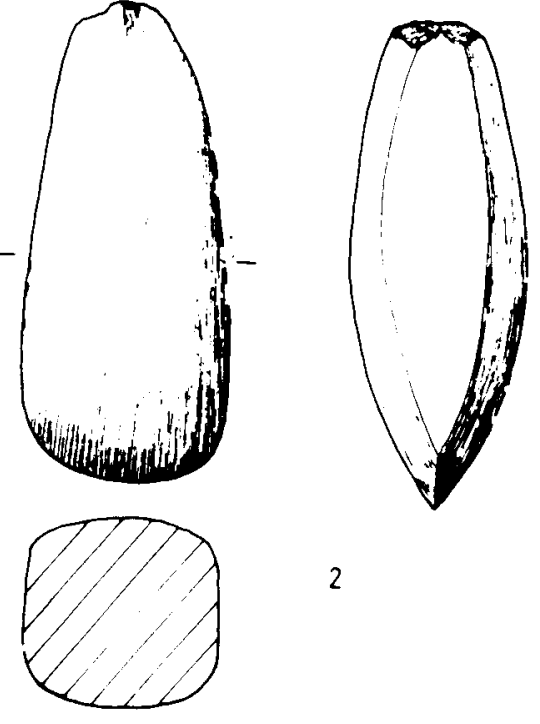

2
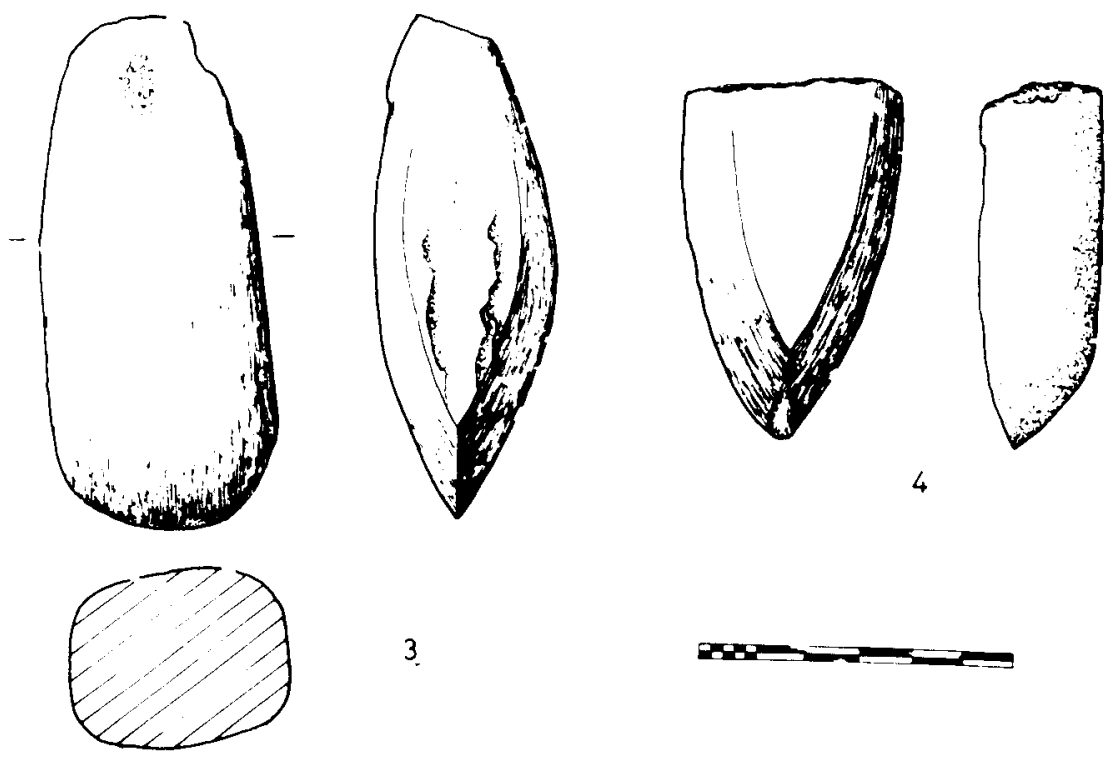

3

Fig. 3. Material de piedra pulida del túmulo 87 . 
N. ${ }^{\circ}$ 3. Hacha tipo I. Materia prima: pizarra nefrítica. Longitud: 100 $\mathrm{mm}$. Anchura: $45 \mathrm{~mm}$. Espesor: $34 \mathrm{~mm}$. Peso: $205 \mathrm{gr}$. (fig. 3,3).

\section{LA: 2,2. A/E: 1,3. L/E: 2,9}

Forma general: trapezoidal. Caras: convexas. Lados: rectos. Aristas: convergentes curvas. Filo: desarrollado, tendente a semicircular. Zona activa: convexo-simétrica. Talón (vista frontal): recto; (vista lateral): truncado. Sección transversal: cuadrangular. Estado de conservación: completa. Desgaste: fracturas en la zona activa; filo romo. Acabado: pulido integral, diferencial entre caras y lados.

N. 4. Hacha tipo I. Materia prima: roca metamórfica. Longitud: 70 mm. Espesor: $41 \mathrm{~mm}$. (fig. 3,4).

Forma general: indefinida. Lados: convexo, el otro lado falta.

Zona activa: convexo-simétrica. Estado de conservación: fragmento distal. Desgaste: filo muy desgastado. Acabado: indeterminado.

N. ${ }^{\circ}$ 5. Hacha tipo II. Materia prima: arenisca. Longitud: $90 \mathrm{~mm}$.

Anchura: $48 \mathrm{~mm}$. Espesor: $29 \mathrm{~mm}$. Peso: $160 \mathrm{gr}$. (fig. 4,1).

L/A: 1,8. A/E: 1,6. LE: 3,1.

Forma general: triangular. Caras: convexas. Lados: convexos. Aristas: convergentes rectas. Zona activa: convexo-simétrica. Talón (vista frontal): redondeado; (vista lateral): irregular. Sección transversal: elíptica. Estado de conservación: completa. Desgaste: fracturas en las zonas proximal y distal; filo obliterado. Acabado: pulido integral, en toda la pieza ${ }^{17}$.

Piedra tallada

N. ${ }^{0}$ 1. Hoja simple. Material: silex. Color: blanquecino. Longitud: 47 $\mathrm{mm}$. Anchura: $14 \mathrm{~mm}$. Espesor: $3,7 \mathrm{~mm}$. (fig. 4,3).

17 Clasificaremos como completos aquellos útiles pulimentados que no hayan sufrido una merma significativa en sus dimensiones. 

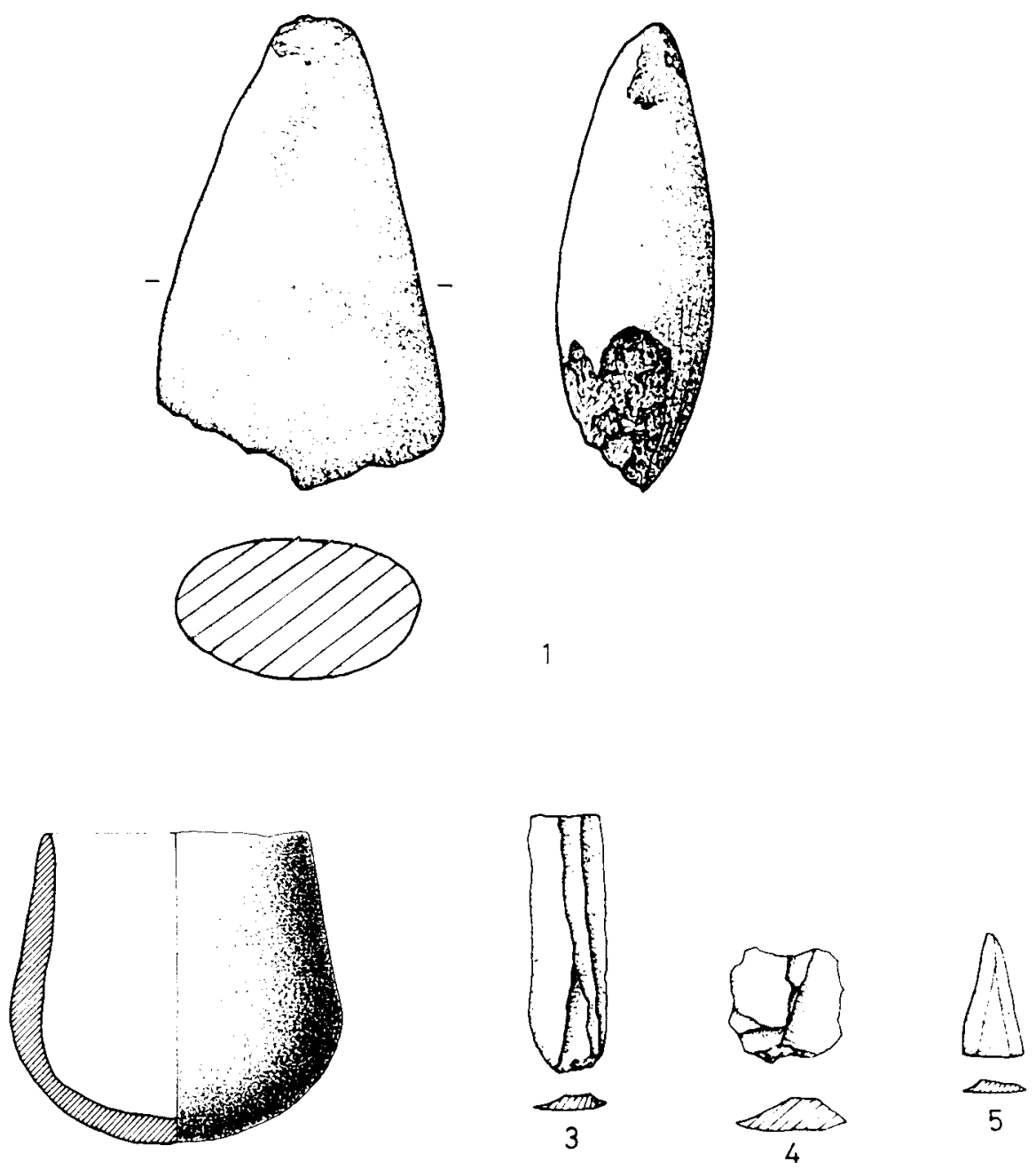

2

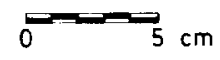

1

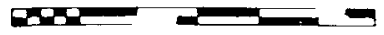

Fig. 4. Material de piedra pulida o tallada del túmulo 87 y vaso de Vilamarin (Orense). 
Tipo de soporte: hoja de tercer orden. Fracturas: distal. Talón: liso, con bulbo prominente. Modificaciones en los filos: microlascados concoidales o en media luna y rounding, en las caras ventral y dorsal, siendo diferencial en ambos filos.

N. ${ }^{\circ}$ 2. Hojita. Material: silex. Color: rosado. Longitud: $22 \mathrm{~mm}$. Anchura: $10 \mathrm{~mm}$. Espesor: $3 \mathrm{~mm}$. (fig. 4,5).

Tipo de soporte: hojita de tercer orden. Fracturas: proximal.

N. ${ }^{\circ}$ 3. Lasca. Material: cuarcita. Color: negro. Longitud: $19 \mathrm{~mm}$. Anchura: $19 \mathrm{~mm}$. Espesor: $8 \mathrm{~mm}$. (fig. 4,4).

Tipo de soporte: lasca de tercer orden. Fracturas: distal. Talón: diedro.

N. ${ }^{\circ}$ 4. Lasca. Material: cuarcita. Color: marrón. Longitud: $47 \mathrm{~mm}$. Anchura: $45 \mathrm{~mm}$. Espesor: $13 \mathrm{~mm}$.

Tipo de soporte: lasca de tercer orden. Talón: liso, con bulbo bastante pronunciado. Modificaciones en los filos: microlascados en media luna en el extremo distal y uno de los lados.

Otros objetos líticos

N. ${ }^{\circ}$ 1. Canto rodado. Material: granito. Longitud: $85 \mathrm{~mm}$. Anchura: $79 \mathrm{~mm}$. Espesor: $49 \mathrm{~mm}$. Conservación: fragmentado transversalmente de antiguo. Desgaste: no se observa.

N. ${ }^{\circ}$ 2. Guijarro. Material: cuarzo lechoso. Longitud: $45 \mathrm{~mm}$. Anchura: $30 \mathrm{~mm}$. Espesor: $18 \mathrm{~mm}$. Forma general: elíptica. Desgaste: no se aprecia, con la excepción de algunos golpes recientes ${ }^{18}$.

${ }^{18}$ Para la ordenación tipológica de los materiales líticos hemos seguido los criterios expuestos por uno de nosotros: FaBREgas VALCARCE, R., Estudio de los materiales liticos de las sepulturas megaliticas de Galicia y Norte de Portugal. Tesis Doctoral microfilmada, UNED, Madrid 1991. 
En términos generales el conjunto del material lítico recuperado en esta sepultura se enmarca bien dentro de las características del megalitismo del Noroeste: pobreza en cuanto al número absoluto de objetos y gran peso especifico del segmento formado por la piedra pulida. Si contemplamos en cambio el ajuar estudiado en un plano comarcal, el monumento número 87 de Serra Faladora se destaca con nitidez de todos los demás tanto por el número como por la variedad de los artefactos. Es cierto que este tipo de consideraciones están viciadas de origen por una serie de factores como son la intensidad y frecuencia de las violaciones o el mayor o merior cuidado puesto en las exploraciones arqueológicas, pero no obstante el número de piezas (11) encontradas se desmarca de lo habitual en los túmulos del extremo septentrional de Galicia, incluso superando en términos cuantitativos a algunos especialmente ricos como el número 229 de Veiga dos Mouros (As Pontes) ${ }^{19}$. También es destacable la aparición, si bien cuantitativamente reducida, de silex, materia prima casi inexistente en los ajuares megaliticos comarcales y que es sustituida por otras rocas o minerales como el cuarzo o la cuarcita, cuya obtención sería ciertamente más fácil. En otro orden de cosas, el material lítico hallado en la mámoa 87 muestra unos rasgos coincidentes con lo usual en el extremo Norte de Galicia, ejemplificados particularmente en la ausencia dentro de contextos megalíticos de puntas de flecha, molinos u objetos cultuales, que están presentes o son incluso abundantes en otras comarcas del Noroeste. Aunque las precarias condiciones de las exploraciones arqueológicas llevadas a efecto en esta zona pueden haber coadyuvado a la pérdida de evidencias sobre algunos de los elementos mencionados, pensamos que su falta en el registro arqueológico puede valorarse en una perspectiva cultural y -tal vez secundariamente- cronológica.

En el apartado de piedra pulida nos encontramos con hachas de los tipos I (tres ejemplares) y II (una pieza), asi como con una azuela de tipo Ila. La proporción entre hachas y azuelas en este yacimiento refleja casi exactamente la que se documenta en el conjunto del Noroeste, donde son mucho más abundantes las primeras que las segundas. Dentro del grupo de las hachas, el tipo I, con piezas más longilíneas y de sección más gruesa, predomina sobre el II, tendencia que se aprecia asimismo en otros monumentos del Norte de Galicia y que contrasta un tanto con la casi igualdad que en términos cuantitativos mantienen ambas variedades en los túmulos del Noroeste. Con los datos disponibles en la actua-

19 Macineira, F., Túmulos prehistóricos. Inventario descriptivo..., citado, págs. 22-28. 
lidad no es posible discriminar cronológicamente entre los dos tipos de hachas, que parecen estar presentes tanto en monumentos cuya construcción se remonta al IV milenio como en contextos más recientes, a veces de forma conjunta, lo cual está atestiguado por el hallazgo de un ejemplar de cada tipo en sendos niveles intactos del pasillo intratumular de Campiños 6 (Rianxo, La Coruña), cuya deposición se data radiocarbónicamente en el $2350 \pm 60$ a C ${ }^{20}$. Creemos, por tanto, que la aparición de uno $u$ otro tipo de hachas puede estar ligada sobre todo a cuestiones de orden cultural o funcional, factores ambos cuya elucidación es todavia problemática en el estado actual de nuestros conocimientos. En un trabajo reciente recogiamos la posibilidad de que algunas hachas del tipo I (aquéllas de sección más acusadamente cuadrada y forma general rectangular) hubiesen sido empleadas como cuñas ${ }^{21}$, mientras que el resto y las del tipo II se emplearian en labores de tala o en el trabajo de la madera.

Ya hemos señalado más atrás la excepcionalidad del hallazgo de utillaje de silex en contextos megalíticos del Ortegal, aunque la representación de este tipo de material en la mámoa 87 se limite de hecho a un fragmento de hoja pequeña y a otro correspondiente a una hojita. Por el contrario, las piezas de cuarcita encuentran paralelos en el vecino túmulo 86, donde Maciñeira encontró varias lascas de ese mismo material, asi como un trozo de prisma de cuarzo con varias extracciones. Esta clase de elementos de piedra tallada carece normalmente de una cronología bien definida y su presencia se detecta en contextos muy dispares, arrancando desde etapas preneolíticas. No obstante, en el caso específico de las hojas de sílex puede advertirse en el conjunto del Noroeste una tendencia hacia la aparición o generalización de ejemplares de gran tamaño dentro de monumentos cuya construcción se sitúa hacia mediados del III milenio, localizándose preferentemente en las inmediaciones del litoral ${ }^{22}$.

Las dos piezas de silex de la mámoa 87 fueron objeto de un análisis de microdesgaste hace unos años ${ }^{23}$, el cual se basó para el establecimiento de la función de dichos objetos en los microlascados observables bajo un microscopio óptico complementado con una lupa binocular. El autor concluye que la hojita sirvió para trabajar con madera muy blanda

20 Fabregas Valcarce y Fuente Andrés, Os Campiños 6..., citado.

21 Fabregas Valcarce, Estudio..., citado.

22 Fabregas Valcarce, Estudio..., citado.

23 Criado Boado, F., Aportaciones al estudio de la economía megalítica: Análisis de microdesgaste en instrumentos líticos, Gallaecia, 6, 1980, págs. 197-205. 
mientras que la hoja habría sido empleada sobre madera ${ }^{24}$. Por nuestra parte hemos procedido a reexaminar éstas y otras piezas con medios ópticos más potentes (microscopio binocular de luz incidente con objetivos oscilando entre $50 x$ y $400 x)^{25}$, los cuales nos han permitido documentar el alto grado de desgaste postdeposicional que habían sufrido los artefactos estudiados, invalidando en la práctica las conclusiones alcanzadas en el análisis funcional llevado a cabo por $\mathrm{F}$. Criado, tanto más cuanto que éste se basaba exclusivamente en los microlascados y estrías. No obstante, si tuviésemos en cuenta meramente los atributos morfológicos que poseen tanto hojas como hojitas, especialmente el agudo ángulo de ataque de sus filos que además presentan un perfil rectilíneo en buena parte de su trazado, las posibilidades de una utilización eficiente se reducen prácticamente a la corta de materiales blandos (carne, vegetales) ${ }^{26}$. No debe olvidarse por último que, especialmente las hojas, pueden haber ido a formar parte del ajuar funerario no tanto en calidad de herramientas sino como soportes que servirian eventualmente para fabricar otros utensilios (puntas de flecha, microlitos, etc...).

Ya en su libro póstumo llamaba Maciñeira la atención hacia la gran frecuencia con que aparecen en túmulos del Ortegal cantos rodados o guijarros traidos ex profeso en ocasiones desde lugares distantes ${ }^{27}$. Este fenómeno no es en modo alguno exclusivo de esa comarca sino que se documenta en otras áreas del Noroeste, especialmente aquéllas que han sido objeto de una exploración más intensiva. La explicación de su presencia puede ser múltiple, dadas las diferencias que se certifican en cuanto a tamaño, materia prima y localización dentro del monumento. En unos casos, su aparición puede ser fruto de la casualidad, aportados en el curso del acarreo de tierras para conformar el túmulo, mientras que en otras ocasiones pueden haber servido como un material constructivo más, ya sea para establecer un pavimento o para acuñar un ortostato. A veces pueden haber sido depositados en las tumbas en calidad de percutores de fortuna, pulidores o incluso como una fuente de materia prima para la ulterior fabricación de útiles. Otros ejemplos sin embargo, parecen demandar una explicación menos pragmática, como cuando los guijarros

24 Criado Boado, Aportaciones..., citado, págs. 200-201.

25 Fabregas Valcarce, Estudio..., Apéndice I: Análisis de microdesgaste sobre artefac. tos tallados.

${ }^{26}$ GRACE, R., Teach yourself microwear analysis: A guide to the interpretation of the function of stone tools. Arqueohistórica, 3, 1989, págs. 47-48; SEMEnov, S. A., Tecnologia prehistórica, Madrid, págs. 213-217; CAHEN, D. y GAspaR, J. P., Les traces d'utilisation des outils préhistoriques, L'Anthropologie, 88, 1984, págs. 295 y 300.

${ }_{27}$ MaciñeIRA, Bares..., citado, pág. 136. 
aparecen localizados junto a objetos cultuales o concentrados en determinadas zonas del monumento ${ }^{28}$, sugiriendo de esta forma una finalidad votiva.

\section{Cerámica}

La cerámica de este túmulo se nos presentaba como un abundante conjunto de fragmentos de reducido tamaño y, por lo tanto, escasamente significativo. Este estado de cosas se modificó en una revisión del material, el cual a pesar de su fragmentación, tal y como ya manifestaba el propio Maciñeira ${ }^{29}$, presenta bastante homogeneidad, expresando su correspondencia a unas totalidades, recipientes o grandes fragmentos, de mucho menor número. El resultado de todo ello fue la posibilidad de unir buena parte de los restos, recuperando así esas realidades cerámicas subyacentes que, constatando la mencionada escasez, constituyen tres vasos que a continuación describimos ${ }^{30}$.

La primera de las piezas reunía la mayoría de los fragmentos conservados, siendo el que sufrió un mayor número de roturas, pues a las antiguas hay que sumar otras de más reciente origen que dificultan la reconstrucción, limitándola a una parte del total de dichos restos. Estas dificultades pueden generar ciertas dudas respecto a la unidad de este conjunto, dudas que son contestadas por la gran homogeneidad en las características técnicas de estos fragmentos, algo extraño en productos manuales y de baja calidad.

Las características técnicas aludidas consisten en una elaboración por el sistema de rodetes (colombins), una materia prima a base de arcilla poco decantada en la que abundan el cuarzo y la mica, que junto con materiales de origen vegetal actúan como degrasante. El acabado es sencillo y se presenta diferenciado, manifestando su mejor calidad en las partes media y alta de la superficie externa, con un aspecto liso y brillante, mientras que esta apariencia se torna más tosca en el interior y base

${ }^{28}$ Un caso particularmente claro se documenta en la mamoa de Outeiro (Baiāo, Oporto), en cuyo límite oriental se encontró un total de 32 guijarros de cuarcita (FARO, S., CLETO, J. y Carneiro, A. L., A escavaçâo da mámoa de Outeiro no contexto do campo Arqueológico da Serrra da Aboboreira, Trabalhos de Antropologia e Etnologia, 28, 1988, pág. 256).

29 MAciñeIRA, Bares... (v. nota 5).

30 Estos restos habian sido dados por perdidos durante tiempo FuENTE ANDRES, F., El material cerámico, en FABREGAS Y FUENTE, Aproximaciones..., citado, pág. 254 y fueron recuperados recientemente ( $v$. nota 4 ). 
de la pieza, ambas provistas de un cepillado irregular. Cabe destacar la presencia en la cara externa de la base de restos del armazón vegetal sobre el que verosimilmente fue elaborado y/o secado el recipiente. La cocción es irregular, aunque con cierto predominio de la oxidante, lo que vendría indicado por una coloración rojizo-acastañada en buena parte de la superficie.

En cuanto a la forma, los fragmentos por si mismos tan sólo nos permiten señalar el predominio o casi exclusividad de la línea curva en su definición. Tres fragmentos de borde de idénticas características añadirían una terminación cerrada con el labio apuntado, diferenciándose mediante una tenue inflexión del resto del vaso. La unión de parte de los fragmentos nos permite una visión de la pieza original, tratándose ésta de un vaso esferoidal de boca muy cerrada (fig. 5).

El segundo conjunto de fragmentos lo componen cinco de mayores dimensiones, cuatro de los cuales se unen formando una pared donde se combinan en una evolución suave la línea recta y la curva (fig. 6). No podemos, sin embargo, determinar concluyentemente la forma global de una pieza que se manifiesta algo diferente a la primera. En este caso estariamos probablemente ante un recipiente de base convexa pero cuerpo tendente a cilíndrico, de forma no muy diferente a la de vasos como el encontrado en un túmulo del alto valle del Barbantiño (Vilamarín, Orense) (fig. 4,2$)^{31}$.

Las otras características de esta pieza presentan también diferencias con respecto al primer vaso descrito. La arcilla sigue estando poco decantada $y$, en lo que a elementos no plásticos se refiere, predominan el cuarzo y la mica, pero la cocción, aún siendo también irregular, es predominantemente reductora, patente en la coloración gris, de diferentes tonalidades (de negruzca a crema). El acabado es aquí tosco y descuidado, manifestándose en la cara interior virtualmente inexistente: superficies totalmente irregulares que todavía conservan las huellas del alfarero, mientras que al exterior tan sólo se consiguen unas superficies algo más regulares pero con abundantes rugosidades.

El tercer conjunto lo forman dos fragmentos de muy pequeñas dimensiones y pésimo estado de conservación. Este último factor impide cualquier aproximación analítica, salvo quizás certificar, atendiendo a la

${ }^{31}$ Eguheta, J. M., Catálogo dos materiais ergolóxicos depositados no Museo de Ourense procedentes de túmulos prehistóricos, Boletín Auriense, 17, 1987, págs. 25-29 (especialmente 25) y fig. 5,1. 
"Mámoa 87 de Serra Faladora”: un túmulo megalítico del Norte de Galicia
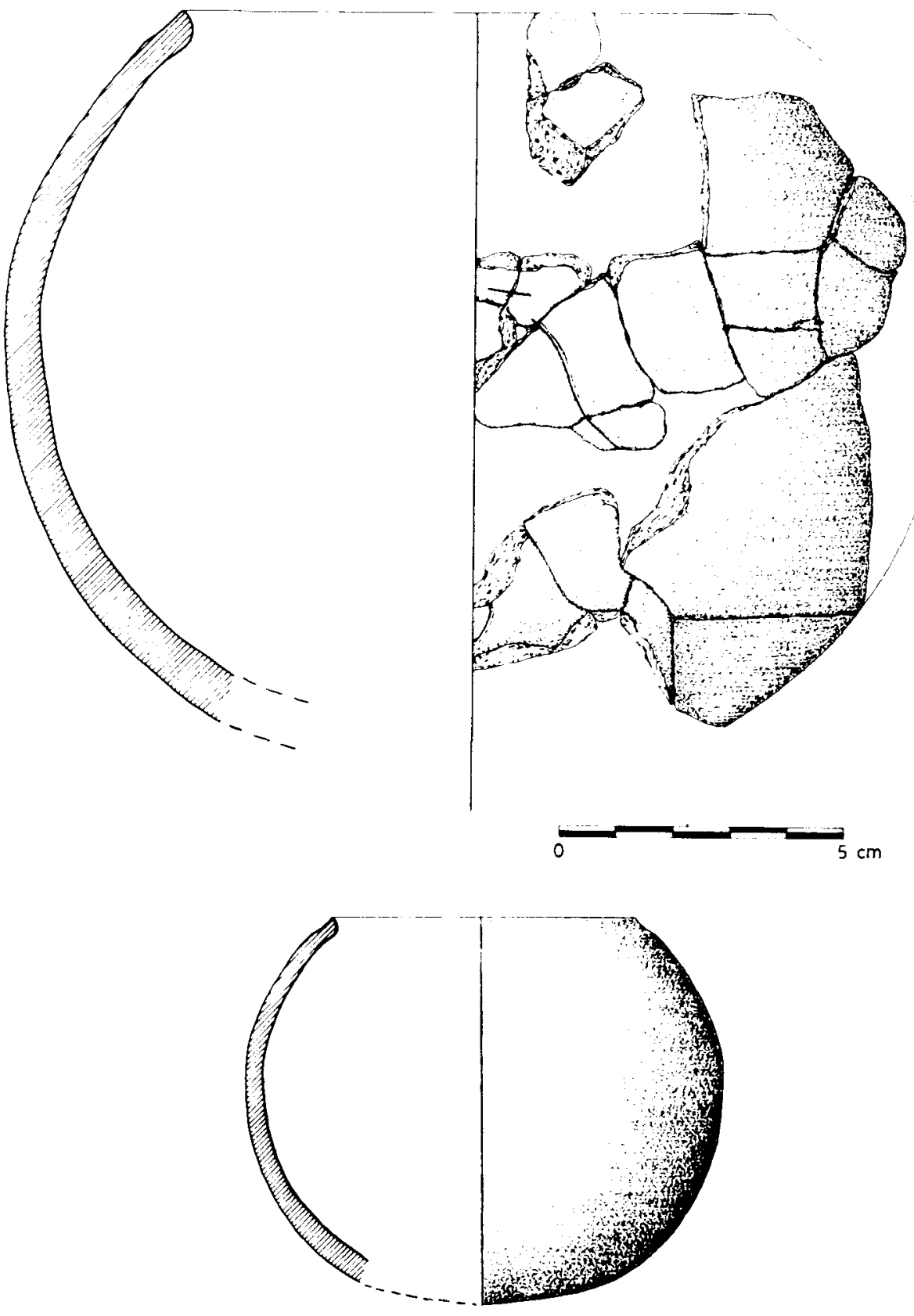

Fig. 5. Fragmentos del vaso $n^{\circ} 1$ y reconstrucción ideal. 

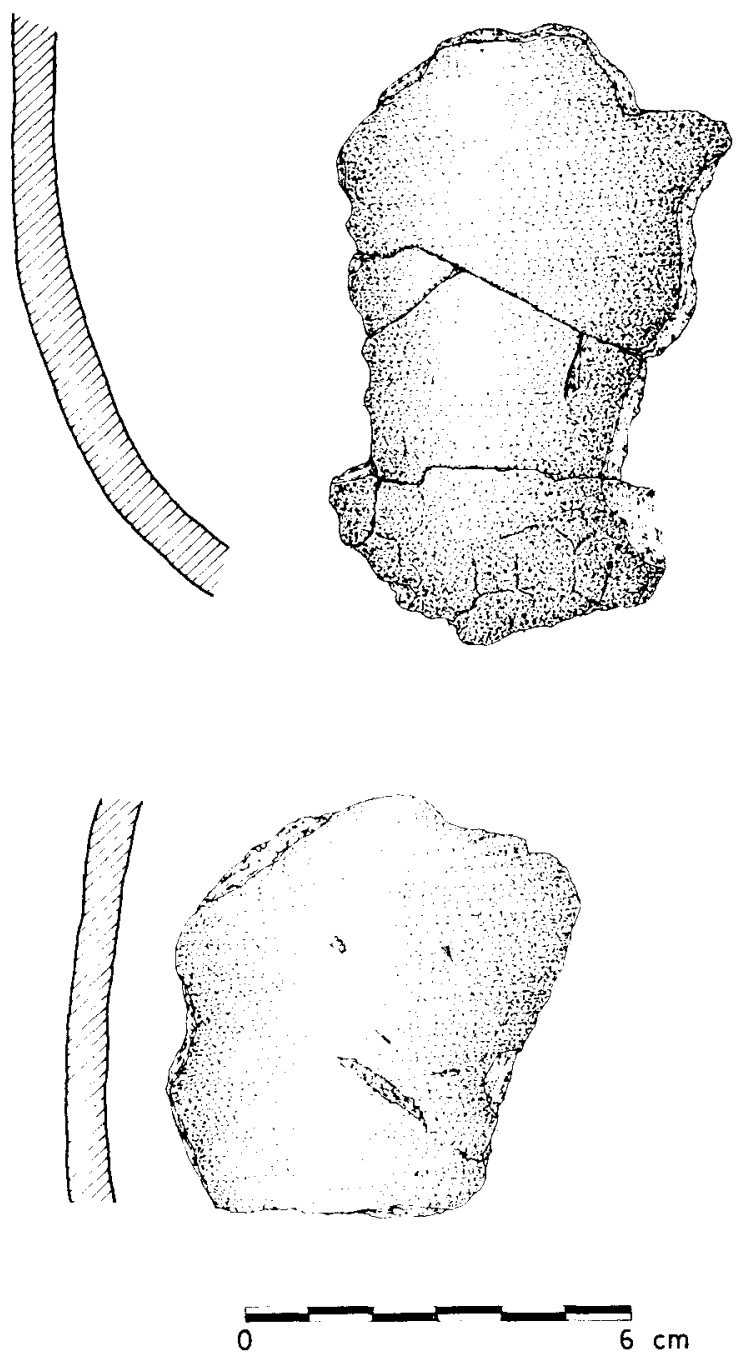

Fig. 6. Fragmentos de la pared del vaso $n .^{\circ} 2$.

pésima calidad de las pastas, su no pertenencia a cualquiera de los otros dos conjuntos.

Por último hay que citar la presencia de un fragmento de cerámica vidriada, al que hay que relacionar con el proceso de saqueo y destrucción del monumento. Por sus rasgos, y a falta de estudios sobre este 
tipo de cerámicas, podemos situarlos en una etapa reciente, entre fines del XVIII e inicios del presente siglo.

A la hora de evaluar las características y conceptualización posible de estas cerámicas, se impone comentar el hecho de su localización geográfica, pues resultan las únicas expresiones de su tipo en contexto megalítico para el extremo Norte de Galicia. En un área que conocemos casi exclusivamente a través de los trabajos de F. Maciñeira ${ }^{32}$, tan sólo el campaniforme se presentaba como un elemento cerámico definido de un megalitismo que hemos de suponer terminal ${ }^{33}$. Si bien es cierto que el autor citado mencionaba la presencia de éstos y otros restos en distintos monumentos, no teníamos hasta el momento unos materiales suficientemente caracterizados como para contrastarlos con las manifestaciones de otras áreas megalíticas del Noroeste ${ }^{34}$.

Los que aquí presentamos parecen manifestar una identidad total con la cerámica que viene siendo entendida como propia del megalitismo, hasta el punto de ser especificamente denominada "megalítica" ${ }^{35}$. Tecnológicamente, todos los fragmentos presentan rasgos que como la tosquedad en su elaboración, fabricación mediante rodetes o el tratamiento diferencial de la parte visible del recipiente, se adecúan a esa definición ya desde una primera observación. El carácter liso de aquéllos insiste en esa identificación.

En to formal, el cuenco esferoidal, representado por nuestro primer ejemplo, responde al tipo más extendido entre cerámica "megalítica", convirtiéndose incluso en exclusivo y definidor en lo morfológico de dicha producción alfarera ${ }^{36}$. El vaso de paredes rectas y base convexa también tiene, a pesar de la indefinición tipológica, un seguro encuadre formal entre los recipientes no esferoidales que en menor cantidad pueblan los ajuares dolménicos gallegos ${ }^{37}$. Son ambos en definitiva una expresión tópica de lo que viene siendo entendido como habitual en el mundo me-

\footnotetext{
${ }^{32}$ Ver Introducción.

${ }^{33}$ MACINEIRA, El vaso campaniforme..., citado.

${ }^{34}$ Un ejemplo de esto lo tenemos en el tratamiento que Maciñeira da a las cerámicas de este túmulo ( $v$. nota 29).

${ }^{35}$ Esta identificación ha sido mayoritaria en la bibliografia sobre el tema y en ella subyace a nuestro entender una concepción errónea del fenómeno megalítico como un hecho cultural unitario.

${ }^{36}$ La ültima sintesis al respecto (FuENTE, El material..., citado) evidencia esa situación.

${ }^{37}$ Consideramos preciso diferenciar tipológicamente estas formas de las esferoides, rompiendo la exclusividad de estas últimas en la definición taxonómica de las cerámicas asociadas al megalitismo.
} 
galítico, homologando asi sus expresiones más septentrionales al resto del Noroeste.

Mayor problema plantea el intentar profundizar en la lectura cronológica y cultural de esta cerámica dentro del fenómeno megalítico. En el primer caso nos enfrentamos a las deficiencias del registro arqueológico que afecta tanto a nuestro monumento como a sus paralelos más inmediatos ${ }^{38}$. Tan sólo podemos plantear relaciones genéricas, como las que vinculan el cuenco esferoidal a los dólmenes de corredor, lo cual encontramos claramente documentado en Argalo ${ }^{39}$, Os Campiños ${ }^{40}$ y Oirós ${ }^{41}$, todos ellos expresión de un megalitismo arquitectónicamente muy desarrollado: grandes cámaras con corredor diferenciado. El túmulo 87 representaría posiblemente frente a los anteriores una versión más reducida y menos ostentosa de dicha solución arquitectónica.

Si atendemos a las cronologías que parecen imponerse para ese tipo de monumentos, centradas en torno a mediados del III milenio ${ }^{42}$, y la posición de posterioridad, al menos parcial, de esta arquitectura con respecto a la basada en cámaras poligonales simples ${ }^{43}$, podríamos datar este tipo cerámico hacia el 2700-2100 a.C.. Su ausencia en contextos tardomegalíticos parece asegurar ese tope final circa $2100^{44}$, pero al desconocer su relación con aquellas fórmulas arquitectónicas del megalitismo más antiguo no podemos concretar por el momento la morfogénesis del cuenco esferoidal liso. Tan sólo existe un caso claro de cerámica en una cámara poligonal simple de ámbito gallego, el túmulo 3 de Parxubeira ${ }^{45}$, la cual aún presentando una morfología semejante - vaso de paredes curvas y boca cerrada- muestra sin embargo unas características muy especificas, como el cuerpo ovoide o el propio hecho de estar decorada,

38 Estas deficiencias son comunes a la mayoria de los monumentos megalíticos. Las mismas no se deben exclusivamente a las limitaciones de los trabajos arqueológicos efectuados en ellos sino que hay que tener en cuenta asimismo la intensa acción de las remociones.

39 Fuente, El material..., citado, págs. 226-233.

40 Fabregas Valcarce y Fuente Andres, Os Campinos $6 . .$. citado.

41 FUENTE, El material..., citado, págs. 248-250.

42 Fábregas Valcarce, R., Cronología y periodización del megalitismo en Galicia y Norte de Portugal, Espacio, tiempo y forma 1, 1988, pág. 288.

43 Hipótesis clásica que los resultados de las dataciones absolutas parecen corroborar en parte.

${ }_{44}$ El uso generalizado del campaniforme como cerámica funeraria y la cada dia mayor presencia de otras especies decoradas, atribuibles a un Calcolítico avanzado o final, permiten suponer que la desaparición de las cerámicas lisas del registro tumular no se debe tanto a la falta de datos como a una mutación en las pautas rituales.

45 Rodriguez Casal, A. A., La necrópolis..., citado, págs. 51 y 69-70. 
haciendo aconsejable su disociación del tipo que estamos tratando. No podemos olvidar, por otro lado, que la pervivencia funcional de estos monumentos a lo largo del tiempo dificulta la valoración cronológica de sus ajuares. Queda así abierto el límite temporal inferior de esta clase de cuencos para el que sólo contamos con la posible datación de los inicios de las sepulturas de corredor, alrededor del 2700 a.C. ${ }^{46}$.

Para los tipos cerámicos que incluyen la aparición de la línea recta, como sería el caso de nuestro segundo ejemplar, no existen contextualizaciones, ni siquiera arquitectónicas, excepto tal vez su posible existencia en el dolmen de corredor de Argalo $^{47}$. Por ello no podemos más que apuntar su convivencia en un mismo monumento con el tipo esferoidal, como seria el caso del túmulo 87 de Serra Faladora o el ya aludido de Argalo, al tiempo que su vinculación a sepulturas de corredor con la lectura cronológica que ya propusimos más arriba. También en el túmulo de A Golada (Pontevedra) se manifiesta esa coincidencia ${ }^{48}$, aunque aquí sin referencias precisas sobre la estructura interna, por lo que no caben valoraciones cronológicas.

Más allá de la cronologia, las posibilidades interpretativas son aún más escasas, pues las deficiencias del registro arqueológico y la escasez de datos limitan el alcance de nuestras aproximaciones. La adecuación de nuestros ejemplares a la definición de cerámica megalítica pasa por una revisión de esta misma, dada la creciente aparición de cerámicas (formas compuestas, con decoración, etc...) que se apartan de los estrechos parámetros utilizados en tal definición (vide supra), lo cual nos lleva a replantearnos cuál seria la ubicación precisa dentro del fenómeno megalítico de piezas como las que se recuperaron en la sepultura estudiada.

Lo cierto es que las formas simples y lisas constituyen aún el segmento fundamental del corpus cerámico megalítico en el Noroeste. Aquellas piezas que por su perfil o la presencia de decoración se salen de esta pauta, no tiene una presencia cuantitativa suficiente como para arrin-

${ }^{46}$ Un dato a tener en cuenta sería la posible existencia de un recipiente cerámico de este tipo en un túmulo trasmontano carente de cámara y de datación presumiblemente antigua (SANCHES, M. J., A mamoa 3 de Pena Mosqueira, Arqueologia, 15, 1978, pág. 16; Idem, 5 datas de C14 para a préhistória recente do Leste de Tras-os-Montes, Arqueologia, 19, 1989, pág. 114).

${ }_{47}$ No son claramente identificables por lo reducido de las dimensiones, pero la disposición formal de los fragmentos conservados hace probable esa lectura tipológica (FUENTE, El material..., citado, fig. 1, 2-7).

${ }^{48}$ Gonzalez, Sor Lucila, Objetos eneolíticos hallados en Golada, El Museo de Pontevedra, 7, 1952, págs. 148-151. 
conar a las anteriores, las cuales transmiten una impresión de homogeneidad al megalitismo en general, cohesionándolo desde la perspectiva ergológica. Por otra parte, en muchos casos esa variabilidad no rompe necesariamente el cuadro cerámico existente sino que lo amplía con nuevas formas o lo enriquece con la inclusión de algún rasgo que, como la decoración, parecia ser ajeno al mismo ${ }^{49}$.

En definitiva, la cerámica del túmulo 87 parece responder a un momento de plenitud de la arquitectura megalítica, circa mediados del III milenio, cuando su presencia podria ser realmente definidora, atendiendo a los ajuares de los grandes monumentos o incluso de aquéllos que como el nuestro constituyen una versión más modesta de los anteriores. Manifiestan estas cerámicas dentro de la homogeneidad ya aludida anteriormente cierta riqueza tipológica: perfiles esferoidales, bursoides, bicónicos..., que quizás, como se aprecia en la recurrencia de dos tipos distintos en los dólmenes más pobres (v. g. mámoa 87 o A Golada), pueda responder a una complementariedad funcional a la hora de constituir el ajuar ${ }^{50}$, o simplemente expresar distintas posibilidades al construir éste. La variabilidad tipológica o, en su caso, funcional se enmarca dentro de un mismo momento, cuyos límites inferiores no estamos todavía en condiciones de precisar. Tampoco podemos delimitar con toda exactitud la específica vinculación existente entre estas cerámicas y el fenómeno megalítico: o bien nos hallamos ante un horizonte caracterizado por cerámicas lisas, con independencia del contexto de que se trate, 0 bien los recipientes sin decoración son seleccionados de entre un conjunto cerámico más variado, a fin de formar parte preferentemente de los ajuares tumulares ${ }^{51}$.

49 En el estado actual de la investigación resulta imposible precisar la relación de estas nuevas fórmulas cerámicas con las ya conocidas. No sabemos aún si será suficiente una ampliación de las taxonomias existentes o si se hará precisa una lectura más diversificada de los artefactos cerámicos asociados al megalitismo.

50 Hipótesis de trabajo a contrastar en el futuro si la fortuna acompaña a los trabajos de campo, pues las condiciones del registro no son favorables a tal comprobación. Como argumento estrictamente analógico conviene recordar los conjuntos de formas diferenciadas en el Calcolitico final (Campaniforme) y Edad de Bronce.

51 Este problema se ha planteado sobre todo a raiz del descubrimiento y estudio de poblados cacolíticos en el Norte de Portugal, con una ergología disímil a la tumular, manifiesta en una importantísima presencia de la cerámica decorada en aquéllos, pero con una cronología pareja a la que se atribuye habitualmente al periodo más desarrollado del megalitismo. Para esta dicotomia ergológica y sus posibles explicaciones ver OLIVEIRA JORGE, S., Datas de C14 para a préhistória recente do Norte de Portugal, Arqueologia, 12, 1985, págs. 174-175; Idem, Povoados da préhistória recente de regiâo de Chaves a Vila Pouca de Aquiar, Porto 1986, vol. Ib. págs. 917-919. 


\section{CONCLUSIONES}

El mundo megalítico del extremo septentrional de Galicia se ha venido mostrando con unos rasgos muy específicos desde el punto de vista arquitectónico: túmulos carentes de cámara o con fosas excavadas en el subsuelo, o estructuras que podrían calificarse de paramegalíticas, como es el caso de ciertos túmulos que en vez de un recinto ortostático albergaban una o dos piedras hincadas verticalmente ${ }^{52}$. Esta clase de monumentos se han atribuido generalmente a una etapa reciente, sino epigónica, del fenómeno megalítico regional. En este marco particular se inserta tanto el túmulo 87 como, probablemente, su vecino 86 , los cuales (con más dudas en el primero) pueden incluirse dentro del grupo de las sepulturas de corredor. Esta caracterización arquitectónica supondría en principio un extrañamiento de estos monumentos con respecto a su contexto local, en el cual escasea este tipo de megalito, aproximándolos sin embargo a lo que es habitual en gran parte del Noroeste. No obstante, esta identificación genérica es matizada por una serie de rasgos que, debido a su ausencia o rareza en otras áreas, sirven para corroborar la especificidad ya comentada del megalitismo en el Norte de Galicia. Nos estamos refiriendo concretamente a la existencia de la fosa subtumular y al descentramiento de la estructura ortostática, sin olvidar las reducidas dimensiones de ambos sepulcros.

El ajuar recuperado en el túmulo objeto de nuestro análisis denota, en buen medida, las caracteristicas más típicas de la cultura material del megalitismo noroccidental en su conjunto: importancia del segmento de piedra pulimentada, aparición dentro del apartado de piedra tallada de hojas u hojitas de silex, si bien de forma testimonial, y presencia de los tipos cerámicos más habituales que llegaron incluso a considerarse como definidores de la alfareria asociada al fenómeno megalítico. Esta adecuación a lo más genérico supone al mismo tiempo un distanciamiento con respecto a las pautas que manifiesta la ergología propia del megalitismo local, la cual se caracterizaría por una especial escasez en los ajuares de la mayoría de las sepulturas, excepto en el caso de determinados monumentos, que corresponderian a momentos avanzados y que albergan en su interior significativos conjuntos, basados bien en la cerámica campaniforme o bien en utensilios perforados como mazas o dobles

52 Este tipo de construcciones, descritas hace años por $F$. Maciñeira, han sido documentadas nuevamente en las excavaciones emprendidas en los últimos años por $X$. Vaquero Lastres en la llanada de As Pontes de Garcia Rodríguez (La Coruña). 
azuelas de piedra pulida. Con todo, no faltan los aspectos concordantes con alguna de las caracteristicas más notables de la zona septentrional, tal es el caso de la ausencia de puntas de flecha, carencia que difícilmente podría atribuirse en exclusiva a problemas de registro ${ }^{53}$.

En definitiva, tanto las caracteristicas de la arquitectura como del ajuar sitúan este monumento en una posición intermedia entre los rasgos más definidores del megalitismo galaico y aquéllos más específicos de la comarca en que se ubica, manifestando al mismo tiempo una ruptura y una reafirmación del particularismo ya mencionado del Norte de Galicia. Esta situación impulsa a plantearse no tanto una matización de ese particularismo como la dinámica que parece afectar al megalitismo en un momento o facies determinados de su desarrollo. En este sentido, la posición ambigua del túmulo 87 de Serra Faladora parecería manifestar un cierto mayor peso de los factores unificadores desde el punto de vista arquitectónico y ergológico sobre aquéllos de carácter más local o regional. Esta tendencia hacia la homogeneidad se correspondería con un horizonte clásico o desarrollado del megalitismo, al cual pertenecen, aunque no en exclusiva, algunos de los elementos que vienen siendo entendidos como más caracteristicos del fenómeno en su conjunto. Esa identificación que como vimos anteriormente recientes estudios ponen en entredicho, podría contemplarse más bien como una consecuencia de un movimiento expansivo, al tiempo que cohesionador, propio de una facies dotada de un especial dinamismo, cuyos reflejos alcanzan incluso a aquellas zonas aparentemente más refractarias, de lo cual tenemos una buena evidencia en el túmulo 87 de Serra Faladora.

53 Fabregas Valcarce, Estudio..., citado. 